\title{
Erratum to: Molecular analysis of miscarriage products using multiplex ligation-dependent probe amplification (MLPA): alternative to conventional karyotype analysis
}

\author{
Ji Won Kim • Sang Woo Lyu $\cdot$ Se Ra Sung • \\ Ji Eun Park • Dong Hyun Cha - Tae Ki Yoon • \\ Jung Jae Ko $\cdot$ Sung Han Shim
}

Published online: 3 September 2014

(C) Springer-Verlag Berlin Heidelberg 2014

\section{Erratum to: Arch Gynecol Obstet \\ DOI 10.1007/s00404-014-3403-5}

By error, the third author's first name (Se Ra) was published with an incorrect spelling in the official publication. The correct first name and the updated author group are given below:

Ji Won Kim · Sang Woo Lyu · Se Ra Sung · Ji Eun Park · Dong Hyun Cha $\cdot$ Tae Ki Yoon · Jung Jae Ko $\cdot$ Sung Han Shim

The online version of the original article can be found under doi:10.1007/s00404-014-3403-5.

J. W. Kim · S. W. Lyu · T. K. Yoon

Department of Obstetrics and Gynecology, Fertility Center of

CHA Gangnam Medical Center, CHA University, Seoul, Korea

S. R. Sung · J. E. Park · S. H. Shim $(\bowtie)$

Genetics Laboratory, Fertility Center of CHA Gangnam Medical

Center, CHA University, Seoul, Korea

e-mail:shshim@cha.ac.kr

D. H. Cha

Department of Obstetrics and Gynecology, CHA Gangnam

Medical Center, CHA University, Seoul, Korea

J. J. Ko

Department of Biomedical Science, College of Life Science,

CHA University, Seoul, Korea 